accumulation and ablation rates are computed at approximately two-week time steps through the seasonal cycle and then summed over the year to obtain the annual net budget.

Using this net-budget parameterization and a solar insolation regime at $120 \mathrm{ka} B P$, preliminary experiments were performed.

First the ice-sheet model was initiated with icefree conditions. In this case it was found that a drop in mean air temperature in all seasons of between 20 and $25 \mathrm{~K}$ was required to initiate an ice sheet. This is a very large mean temperature change; however, it must be viewed with caution for two reasons. First, the reduction of the mean annual temperature is probably not climatically realistic. In the model there is a decrease the in winter snowfall due to its dependence on saturation vapor pressure, despite the cooling. Second, there are computational constraints in defining the surface albedo that are presently part of the model which may enhance the difficulty in initiating an ice sheet.

The reason for the difficulty in initiating the growth of an ice sheet from ice-free conditions is that low summer albedos associated with these conditions increase the amount of absorbed solar radiation to such an extent that any modest decrease in air temperature is overwhelmed resulting in complete snow/ice ablation.

In order to examine how important the surface albedo is to the inititiation of an ice sheet a few experiments were performed which were initiated with a ten meter ice field with a surface albedo ranging from 0.7 to 0.8 . In the case when the snow/ice surface albedo was set to 0.8 a reduction in mean air temperature of only $3 \mathrm{~K}$ produced ice-sheet growth with about $350 \mathrm{~m}$ of ice accumulating at $72.5^{\circ} \mathrm{N}$ after $5 \mathrm{ka}$. This was the only case in these preliminary experiments which produced ice-sheet growth. In the cases where the snow/ice surface albedo was set to 0.8 and 0.75 and the mean air temperature was decreased 2.5 and $3 \mathrm{~K}$ respectively the $10 \mathrm{~m}$-ice field melted away slowly with a residual ice field, present after $1 \mathrm{ka}$, completely disappearing after 5 $\mathrm{ka}$. In other experiments in which the snow/ice surface albedo was set to 0.8 and mean air temperature was decreased $2 \mathrm{~K}$, and in which the snow/ice surface albedo was set to 0.7 and mean air temperature was decreased $2.25,3$ and $4 \mathrm{~K}$, the $10 \mathrm{~m}$-ice field melted away within the first thousand years.

Despite the fact that these results are preliminary and must be viewed with caution, the magnitude of the difference between the reduction in mean air temperature required to initiate ice-sheet growth when an initial ice field is assumed compared to when ice-free conditions are assumed is quite large. This suggests the critical importance of the summer surface albedo in determining ice-sheet initiation.

In conclusion, these results suggest that there is great difficulty in making the transition from interglacial to glacial conditions using zonallyaveraged conditions, and that making that transition requires the crossing of a climatic threshold in which ice and snow accumulation in the winter season, and thus high surface albedo, can be maintained through the summer season.

\section{REFERENCES}

Derlemans J, Bienfait J M 1981 Linking ice sheet evolution to Milankovitch radiation variations: a model simulation of the global ice volume record. In Soleil et climat. Joumées d'études inter nationales. Toulouse...1980. Toulouse, Centre National d'Etudes Spatiales: 357-368

Pollard D 1982 A simple ice sheet model yields realistic $100 \mathrm{kyr}$ glacial cycles. Nature 296(5855): 334-338

\title{
THE PREDICTABILITY OF GLACIATION CYCLES
}

\section{(Abstract)}

\author{
by
}

\author{
H. Le Treut
}

(Laboratoire de Météorologie Dynamique, 24 rue Lhomond, 75231 Paris Cedex 05, France)

and M. Ghil

(Courant Institute of Mathematical Sciences, New York University, 251 Mercer Street,

New York, New York 10012 , U.S.A.)

We consider a nonlinear climatic oscillator, which includes radiation balance, oceanic thermal inertia, a highly simplified hydrological cycle, the mass balance and the plastic flow of ice sheets, and the elasticity of the Earth's lithosphere and the viscosity of its mantle, as well as their various interactions. The study of the unforced behaviour of the system (Källén and others 1979, Ghil and Le Treut 1981, Ghil and Ravantzis in press) has shown the existence of a self-sustained periodic oscillation with amplitude of a few degrees Celsius, in the absence of any periodic forcing. The free period of the oscillator, depending on model parameters, lies roughly between 5 and $15 \mathrm{ka}$.

The forced oscillations of this climatic oscillator is studied next (Le Treut and Ghil 1983, Ghil in press): the model is subjected to forcing at the astronomical periodicities of precession 19 and $23 \mathrm{ka}$, obliquity $41 \mathrm{ka}$, and eccentricity 100 and $400 \mathrm{ka}$. The forcing is assumed to act on the climatic system by variations in mean annual isolation, in the case of eccentricity, as well as by $i$ ts effects on the ice-mass balance through the nonlinear precipitation-temperature feedback.

The effects investigated cause only small changes in ice-mass $V$ and global temperature $T$ when selfsustained oscillations are absent. In their presence, a nonlinear resonant response to the forcing leads to large changes in $T$ and $V$. The systematic study of the Fourier power spectrum for various conditions of forcing gives an insight into the dynamics of the model. For low values of forcing, the response is at the frequency of the free oscillation, at the frequency of the forcing and at combination tones of these.

For higher values of the forcing, due to the mechanism of frequency locking (entrainment), the 
frequency of the free oscillation disappears from the spectrum and is replaced by the harmonic of a forcing frequency. In all cases, the nonlinear character of the response also leads to combination tones, i.e. to 1 inear combinations of the forcing frequencies with integer coefficients. Among these frequencies, the largest peaks occur near 100 and $10 \mathrm{ka}$. The peak near $100 \mathrm{ka}$ corresponds to a re-synthetization of the eccentricity period when the model is forced at the precessional periods.

Detrainment (loss of frequency locking) leads to a change in the spectrum of the model: the sharp peaks in spectral density at the forcing frequencies and at their combination tones become superimposed on a continuous background. The spectral power in the background decreases with increasing frequency, like random red noise. The deterministic aperiodic behaviour associated with this frequency-dependent background leads to a loss of predictability which is studied first by comparing model solutions with different initial conditions. Small differences in the initial conditions produce errors as large as the total amplitude of model solutions in a time of the order of $100 \mathrm{ka}$.

We have also investigated the properties of the lagged-correlation function of the model (Le Treut and Ghil 1983, Ghil in press). In the case of a perfectly periodic solution, the autocorrelation is perfectly periodic itself with an amplitude equal to 1 . In the case of a red noise-like signal, the amplitude of the lagged correlation decreases exponentially with a characteristic decay time corresponding to the relaxation time of the model. For those cases in which a line spectrum is superimposed on a continuous spectrum, we observe first an exponential decay of the lagged correlations, leaving a residual periodic or quasi-periodic part of amplitude considerably smaller than 1 .

These results suggest that the ability to simulate accurately the palaeoclimatic history of the Earth decreases with the length of simulated time. Complete lack of correlation between a simulated history and one reconstructed from data is likely to occur over a time interval of 100 to $1000 \mathrm{ka}$.
Spectral information, on the other hand, is considerably more robust (Hays and others 1976 Oerlemans 1982, Le Treut and Ghil 1983, Ghil in press). Changes in the spectrum in different proxy records between early and late Pleistocene, for instance, might be statistically significant. Further modelling efforts are desirable to ascertain whether these are due to changes internal to the climatic system (Sergin $1980)$ or to changes in orbital frequencies and amplitudes over the time scale of $1000 \mathrm{ka}$. (Buys and Ghil in press).

\section{REFERENCES}

Buys M, Ghil M In press Mathematical methods of celestial mechanics illustrated by a simple model of planetary motions. In Berger $\mathrm{A}$, Hays $\mathrm{J}$, Imbrie J, Saltzman B (eds) Milankovitch and climate: understanding the response to orbital forcing. Dordrecht, Reidel Publishing Co.

Ghil $M$ In press Theoretical climate dynamics: an introduction. In Ghil M, Benzi R, Parisi G (eds) Turbulence and predictability in geophysical fluid dynamies and climate dynamics. Amsterdam, NorthHoll and Publishing Co.

Ghil M, Le Treut H 1981 A climate model with cryodynamics and geodynamics. Joumal of Geophysical Research 86(C6): 5262-5270

Ghil M, Ravantzis J In press Global Hopf bifurcation in a simple climate model. SIAM Journal on Applied Mathematics

Hays J D, Imbrie J, Shackleton N J 1976 Variations in the Earth's orbit: pacemaker of the ice ages. Science 194(4270): 1121-1132

Källén E, Crafoord C, Ghil M 1979 Free oscillations in a climate model with ice-sheet dynamics. Joumal of the Atmosphemic Sciences 36(12): 2292-2303

Le Treut H, Ghil M 1983 Orbital forcing, climatic interactions, and glaciation cycles. Joumal of Geophysical Research 88(C9): 5167-5190

Oerlemans J 1982 Glacial cycles and ice-sheet modelling. Climatic Change 4: 353-374

Sergin V Ya 1980 Origin and mechanism of largescale climatic oscillations. Science 209: 1477-1480 